\title{
Cascadia megathrust earthquake rupture model constrained by geodetic fault locking
}

\author{
Duo $\mathrm{Li}^{* 1}$ and Yajing $\mathrm{Liu}^{2}$ \\ ${ }^{1}$ Department of Earth and Environmental Sciences, Munich University, Theresienstr. 41, \\ Munich, Germany \\ ${ }^{2}$ Department of Earth and Planetary Sciences, McGill University, 3450 University Street, \\ Montreal, Quebec, Canada
}

Nov. 6th, 2020

\begin{abstract}
Paleo-earthquakes along the Cascadia subduction zone inferred from offshore sediments and Japan coastal tsunami deposits approximated to M9+ and ruptured the entire margin. However, due to the lack of modern megathrust earthquake records and generally quiescence of subduction fault seismicity, the potential megathrust rupture scenario and influence of downdip limit of the seismogenic zone are still obscure. In this study we present a numerical simulation of Cascadia subduction zone earthquake sequences in the laboratory-derived rate-and-state friction framework to investigate the potential influence of the geodetic fault locking on the megathrust sequences. We consider the rate-state friction stability parameter constrained by geodetic fault locking models derived from decadal GPS records, tidal gauge, and leveling-derived uplift rate data along the Cascadia margin. We incorporate historical coseismic subsidence inferred from coastal marine sediments to validate our coseismic rupture scenarios. Earthquake rupture pattern is strongly controlled by the downdip width of the seismogenic, velocity-weakening zone, and by the earthquake nucleation zone size. In our model, along-strike heterogeneous characteristic slip distance is required to generate margin-wide ruptures that result in reasonable agreement between the synthetic and observed coastal subsidence for the A.D. 1700 Cascadia $\mathrm{Mw} \sim 9.0$ megathrust rupture. Our results suggest geodetically inferred fault locking model can provide a useful constraint on earthquake rupture scenarios in subduction zones.
\end{abstract}

\section{Introduction}

Earthquakes are usually recognized as frictional instabilities resulted from long-term loading on tectonic faults [1]. The great population along the Cascadia subduction margin - the convergent plate boundary between the Northern American and Juan de Fuca plates - makes it important to investigate the potential hazard of future megathrust earthquakes. In particular, seismic and tsunami hazards will be strongly affected by the total amount of coseismic slip and the downdip extent where the fault rupture might propagate and arrest.

\footnotetext{
*dli@geophysik.uni-muenchen.de

${ }^{1}$ Li D, Liu Y. 2021 Cascadia megathrust earthquake rupture model constrained by geodetic fault locking. Phil. Trans. R. Soc. A 379: 20200135. https://doi.org/10.1098/rsta.2020.0135
} 
Our current understanding of Cascadia megathrust ruptures largely relies on the historical records from marine sediment turbidities [2] and coastal coseismic subsidence data inferred from sediment marshes [3], due to the lack of modern seismological records. Historically, several megathrust earthquakes have struck the margin [2, 6] and generated strong ground shaking [7] and high tsunami waves across the Pacific ocean [4]. The estimated magnitude is approximately up to M9+ [2]. Static coseismic slip patches can also be calculated using constraints from historical megathrust earthquake records. By comparing with the coastal subsidence data, Wang et al. [11] constructed an elastic dislocation model to estimate the coseismic rupture size and spatial extent of the A.D. 1700 earthquake. They showed coseismic slip is segmented in five patches with varying downdip limits along the margin during the M9+ event. The downdip extent of the coseismic ruptures is roughly consistent with the thermal constraint proposed for transition to stable slip behavior, with some minor differences [9, 12].

Several factors might influence the subduction earthquake rupture extent. From a rock frictional strength perspective, earthquakes are not able to nucleate above certain temperatures where rock plasticity onsets (e.g., $350^{\circ} \mathrm{C}$ for granite gauges). The temperature threshold depends on many properties such as the rock type, confining pressure, and presence of pore fluids in the fault gouge $[1,15]$. Without additional dynamic weakening mechanisms, coseismic ruptures tend to slow down and stop when propagating into such high temperature regimes [33]. Geodetic locking inferred from continuous displacement measurements along subduction zones provides a useful proxy for the potential extent of future megathrust ruptures. The geodetic inversion results are commonly presented as a spatially variable fault locking coefficient $(\phi)$ between 0 and 1 ; a high locking coefficient implies mechanically coupled fault where a large amount of strain energy is accumulated toward a sudden release in a dynamic earthquake, whereas a low locking coefficient implies nearly free sliding between the subducting and overlying plates and little strain energy is reserved for seismic release.

Geodetic locking inversion for the Cascadia subduction zone has utilized mainly two types of surface displacement measurements. The first type uses tidal and leveling records in western Oregon and northern California from 1925 to 2006 to constrain an elastic dislocation model for plate locking (referred to as Burgette model) [18]. The second type analyzes decadal continuous GPS along the Cascadia margin (referred to as Schmalzle model) [5, 44]. Both sets of inversion results share some general first-order features, such as the widening of the locked zone offshore Washington due to the shallower dipping oceanic slab [46], and generally narrower locking zone and lower locking coefficient offshore Oregon (Fig. 1). The latter is recently proposed to be related to lower sub-slab buoyancy, which may also be responsible for the forearc topography variation along the margin [16]. The downdip end of the geodetically inferred locking zone is roughly consistent with the depth of $\sim 350^{\circ} \mathrm{C}$ friction stability transition temperature from Cascadia geothermal models $[8]$. Noticeable differences also exist between the two sets of inversion results. Burgette et al. [18] found that distinct changes in the locking depths are required offshore Oregon (latitude $\sim 42^{\circ} \mathrm{N}$ and $\sim 45$ ${ }^{\circ} \mathrm{N}$ ), which results in a narrower locked zone (Fig. 1]b). Such abrupt along-strike variation in locking depths is not required in the Schmalzle model [5]. Comparing the two locking models (Fig. 1), we also note that the Schmalzle [5] model shows a significantly higher degree of locking than the Burgette [18] model at the shallowest $10 \mathrm{~km}$ for most of the margin south of latitude $\sim 47^{\circ} \mathrm{N}$.

The above differences in the two types of geodetic locking models can have significant implications for Cascadia megathrust earthquake rupture scenarios. For example, as the $\phi=0$ locking depth from the Burgette model is mostly offshore, it would indicate entirely free sliding further downdip where no seismic slip would propagate into. By contrast, the zero locking depth of the Schmalzle model extends moderately onshore, which implies nonzero coseismic slip and stronger ground shaking for the coastal population. Except for the segment north of latitude $\sim 47.5^{\circ} \mathrm{N}$, 
the lower locking degree of the Burgette2009 model, on average 0.5, also predicts generally smaller coseismic slip.

Numerical models using the empirical rate-and-state friction law can simulate the slip and stress history on the fault during earthquake cycles spanning a continuum spectrum of fast and slow slip [e.g. 25, 26, 27, 28, 29, 31, 32, 38, 49]. For example, Kaneko et al. [30] showed that interseismic fault coupling pattern is highly related to the heterogeneous frictional properties on the fault, which suggests that geodetic inversions of fault locking can be used to inform the rate-state frictional parameter distributions in such earthquake sequence models and hence to quantitatively assess earthquake rupture scenarios.

To investigate the possible scenarios of Cascadia megathrust earthquake ruptures, we construct a 3D subduction fault model in the rate-and-state friction framework with friction parameters constrained respectively by the Schmalzle (Model I) and Burgette (Model II) geodetic locking models. Specifically, the geodetic locking pattern is mapped to the rate-state friction stability parameter $a-b$ on the fault, assuming the relative amplitude of $a-b$ is proportional to the degree of fault locking as expressed in the coupling coefficient $\phi$. The historical coseismic subsidence data from coastal sediment measurements [11] are used as observational constraints to compare to the synthetic surface deformation generated from the coseismic slip from Models I and II. We find that Model I could reproduce the surface subsidence data comparable to the historical observations within the uncertainty range. Additionally, the coastal subsidence pattern requires heterogeneous, rather than uniform, earthquake nucleation sizes (the minimum fault length for nucleating an earthquake) along the fault in order to generate coseismic rupture along the entire margin.

In the following sections, we first introduce the coastal subsidence dataset used in the comparison to our model predicted coseismic surface displacement (Section 2). Numerical model setup and results are presented in Sections 3 and 4 respectively, followed by discussion on model limitations and implications in Section 5 .

\section{Coastal Subsidence Data}

Stratigraphic sequences of coastal marshes can record abrupt subsidence during coseismic ruptures [6]. The coastal sediments will appear above a buried soil layer and thus can be dated with radiocarbon method [3]. A 6500-year history of coseismic displacements of great earthquakes has been recovered from the coastal marshes along the Cascadia margin [3], which provides a unique database to study the megathrust earthquake sequences. The times and spatial extents of the historical coseismic ruptures inferred from the onshore marsh sediments have been correlated with the marine turbidites data [2]. Radiocarbon dating and deposit thickness measurement can be used to constrain the amplitude of surface deformation and estimate the earthquake magnitudes [3].

The most recent Cascadia megathrust rupture in A.D. 1700 was simultaneously recorded by coastal tsunami sediments in Japan [6] and Cascadia marine turbidites [2], and thus has a relatively precise time estimate. The coastal subsidence data obtained for this A.D. 1700 megathrust event are initially from Leonard et al. [3] and later refined by Wang et al.[11] using chronological techniques with microfossil assemblages. Tracing coastal deposits with microfossil features can narrow the uncertainty ranges of paleo-elevations before megathrust earthquakes [3, 11], which are derived from fitting the data with a Gaussian probability distribution [11] (Fig. 1c).

The coastal subsidence measurement has been used as a constraint for the downdip limit of the Cascadia seismogenic zone. Both uniform and heterogeneous elastic dislocation models informed by such coastal subsidence dataset have been developed to describe the rupture magnitude and spatial extent of these historical earthquakes [3, 11]. We use the coastal subsidence generated by 

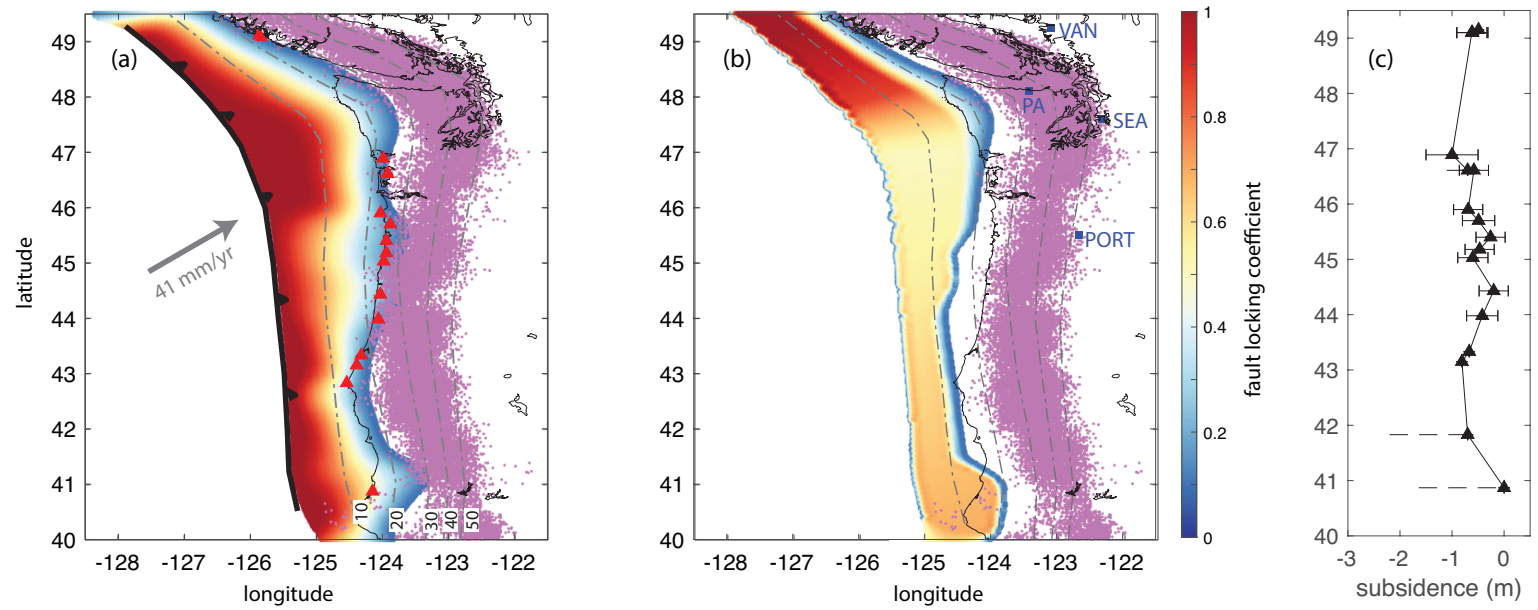

Figure 1: Maps showing fault locking coefficients $\phi$ of (a) Model I: from Schmalzle et al. [2014][5] and (b) Model II: from Burgette et al. [2009] [18]. Plate convergence rate $V_{p l}$ is set to be $41 \mathrm{~mm} / \mathrm{yr}$. Light purple dots are non-volcanic tremor locations of from 2018 to 2020 from Pacific Northwest Seismic Network (PNSN https://pnsn.org/tremor). Dashed lines are depth contours. Red triangles are coastal sedimentation sites used originally by Leonard et al. [2010] [3] and later by Wang et al. [2013] [11]. Cities: PORT: Portland, SEA: Seattle, PA: Port Angeles. VAN: Vancouver. (c) Historical subsidence data from Wang et al. [2013][11]. Black triangles with error bars: subsidence data corrected with transfer functions based on a Gaussian probability distribution. Black triangles with dashed line: subsidence range estimated without transfer functions due to insufficient data coverage.

the A.D. 1700 megathrust earthquake to compare the surface displacements calculated from our modeled coseismic slip. The coastal sediment sites used in this study are from the Washington State to northern California as shown in Fig. 1a.

\section{Model setup}

We model the subduction fault as a planar surface embedded in an elastic half-space medium. Our study domain extends from $40^{\circ} \mathrm{N}$ to $50^{\circ} \mathrm{N}$ covering the entire Cascadia subduction zone, as shown in Fig. 1. We first rotate the slab into trench-normal and trench-parallel coordinates. Y-axis is set to trench-parallel (along-strike) and $\mathrm{X}$-axis is trench-normal (downdip). The fault is $1100 \mathrm{~km}$ long in the along-strike and $492 \mathrm{~km}$ wide in the downdip distance, assuming a constant dipping angle of $13^{\circ}$, which represents the average dipping angle for the shallow $30 \mathrm{~km}$ of the Cascadia subduction fault. $X=0 \mathrm{~km}$ corresponds to the trench location. The fault contains 1024 evenly-spaced grids along the strike and 384 along the downdip direction, resulting in 393,216 rectangular elements in total. Each rectangle has an area of 1.07 (trench-parallel) $\times 1.28$ (downdip) $\mathrm{km}^{2}$. The fault is loaded along the downdip direction at a constant rate of $41 \mathrm{~mm} / \mathrm{yr}$.

\subsection{Governing Equations}

We assume that fault shear strength is governed by the laboratory-derived rate- and state-dependent friction law [20, 53]. The friction coefficient $f$ is a function of both the slip rate $V$ and a single 
state variable $\theta$,

$$
\tau=\bar{\sigma} f=(\sigma-p)\left[f_{0}+a \ln \left(\frac{V}{V_{0}}\right)+b \ln \left(\frac{V_{0} \theta}{d_{c}}\right)\right] .
$$

Here, $a$ and $b$ are non-dimensional friction parameters, $d_{c}$ is the characteristic distance over which $\theta$ evolves following velocity steps, $f_{0}$ is the friction coefficient at a reference velocity $V_{0}$ at steady state, and $\bar{\sigma}=\sigma-p$ is the effective normal stress defined as the difference between normal stress (lithostatic) and pore fluid pressure.

There are two commonly used state variable evolution laws. The "aging" law allows friction to evolve on stationary asperity contacts as supported by laboratory experiments [14]. The "slip" law requires nonzero slip for friction evolution and has been shown to better represent the friction evolution during earthquake nucleation especially at large velocity steps [13]. Here we use the "aging" law

$$
\frac{d \theta}{d t}=1-\frac{V \theta}{d_{c}}
$$

At steady state $\theta_{s s}=d_{c} / V$, frictional coefficient becomes $f_{s s}=f_{0}+(a-b) \ln \frac{V}{V_{0}}$. Slip remains stable and any slip perturbation evolves towards the steady state when the friction stability parameter $a-b$ is positive (velocity-strengthening, VS). Slip can be either unstable or conditionally stable when $a-b$ is negative (velocity-weakening, VW).

The conditionally stable slip mode appears when the fault width under velocity-weakening $(W)$ is comparable to but less than the minimum size for unstable slip, namely the characteristic nucleation size, $h^{*}$, which is related to the rate-and-state friction parameters $a, b, d_{c}$ and $\bar{\sigma}$, as first formulated by Rice and Ruina [50], Rice [49]. More recently, Rubin and Ampuero [52] define $h_{R A}^{*}$ as the size of expanding crack governed by fracture energy balance during propagation:

$$
h_{R A}^{*}=\frac{2 \mu b d_{c}}{\pi(1-\nu)(b-a)^{2} \bar{\sigma}}
$$

Although the subduction fault is assumed to be planar with the major advantage of saving computational time and allowing more extensive parameter space search, the 3D fault geometry is to the first order reflected by the variation of the along-dip seismogenic zone width, which as shown in previous studies [38] strongly affects the earthquake nucleation and rupture propagation in the combination of $W / h^{*}$.

The quasi-dynamic relation between the shear stress and fault slip is introduced by [49] with radiation damping approximation,

$$
\tau_{i}(t)=-\sum_{j=1}^{N} K_{i, j}\left(\delta_{j}(t)-V_{p l} t\right)-\eta \frac{d \delta_{i}(t)}{d t},
$$

where $\tau_{i}(t)$ and $\delta_{i}(t)$ are shear stress and displacement of the $i$ th element on the fault, respectively. Stiffness kernel $K_{i, j}$ is the shear stress change on element $i$ from a unit dislocation in the dip direction on element $j$, and thus has the unit of stress/distance. $K_{i, j}$ is the stiffness kernel calculated from the quasi-static solution for a uniform slip over a rectangular dislocation on a cell in an elastic half-space [35]. The radiation damping factor $\eta=\mu / 2 c_{s}$ ( $\mu$ is the shear modulus and $c_{s}$ is the shear wave speed) is introduced to prevent the slip velocity from going unbounded during an earthquake [49]. Plate convergence rate $V_{p l}=41 \mathrm{~mm} / \mathrm{yr}$ is constant with time.

Compared with the full dynamic simulation, the quasi-dynamic approach can produce similar seismic cycles but with lower seismic rupture propagation speeds and longer co-seismic duration $[32,33]$. Here we focus on the long-term earthquake sequence behavior, and use the cumulative 
coseismic slip, instead of detailed rupture process, for the surface displacement calculation that is to be compared with the coastal subsidence data. Therefore, the dynamic stress radiation is ignored in the current model.

\subsection{Parameter Choices}

Friction stability parameter $\mathbf{a}-\mathbf{b}$ The non-dimensional friction stability parameter $a-b$ depends on temperature, rock type, and normal stress in friction experiments [e.g. 15, 43]. In rate-state friction numercal modeling studies, the depth-dependent $a-b$ distribution is typically obtained by converting $a-b$ measured on granite or gabbro gouge shear experiments under hydrothermal conditions [22, 23] using a temperature profile for the fault zone of interest [34, 37].

Here we assume fault friction stability is constrained by the fault locking pattern; the nondimensional parameter $a-b$ scales linearly with fault locking coefficient $\phi$. Specifically, in the velocity-weakening zone, a more negative $(a-b)$ (larger $b-a$ ) corresponds to a larger locking coefficient. When all other parameters are held constant, larger $(b-a)$ results in a smaller nucleation size $h^{*}$ (equation 3.3), hence larger $W / h^{*}$, which has been numerically shown to scale with the average seismic coupling coefficient in a comprehensive oceanic transform fault earthquake sequence model [40]. Here, we use two sets of fault locking coefficient patterns, $\phi$, from the geodetic inversions: 1) Model I: using dense GPS arrays from 1991 to 2014, assuming $\phi$ is equal to 1 at the trench and follows a Gamma model where $\phi$ decrease from 1 to 0 exponentially with the landward distance from the trench [5], and 2) Model II: using coastal tidal gauges and leveling-derived uplift rates in Oregon and California [18]. The fault locking patterns are projected to the planar fault according to the downdip distance.

The fault locking coefficients $\phi$ of both models are shown in Fig. 1. The major difference in the two pattern appears near the border of Washington and Oregon. In the study of Schmalzle et al. [5], the fault locks further landward in Washington and northern California (Fig. 1a). In the result of Burgette et al. [18] shown in Fig. 1 b, the fault is only firmly locked offshore on southern Vancouver Island. From Washington to northern California, the fault locking decreases from about 1 to 0.5 and then increases to 0.9 in the southern end. The along-strike variation of $\phi$ in Oregon and northern California is constrained with tidal and sea-level data while with GPS inversions in Washington and southern Vancouver Island [18].

To convert $\phi$ to parameters $a-b$, we first set a cutoff value as $\phi_{c}$ where the downdip velocityweakening to velocity-strengthening $a-b=0$ takes place. In Model I (schmalzle Gamma model), we choose $\phi_{c}=0.55$. In Model II (Burgette model), we choose $\phi_{c}=0.2$. Between $\phi=1$ and $\phi=\phi_{c}$, $a-b$ increases linearly from -0.0035 to 0 . Further downdip, $a-b$ linearly increase from 0 to 0.0035 when $\phi$ decreasing from $\phi_{c}$ to 0 (Fig. 2). We also test choosing $\phi_{c}=0.4$ and 0.5 in Model II, results of which are shown in the Supplementary Materials Fig. S1-S2

Characteristic nucleation size $h^{*}$ Numerical studies in the framework of rate-state friction have demonstrated that earthquake and slow slip source characteristics are largely controlled by the length ratio between the seismogenic zone size (downdip width of the velocity-weakening zone) and the characteristic nucleation zone size, $W / h^{*}[37,40,51]$. Here $h^{*}$ is calculated using Eq. 3.3. As $W$ is constrained by downdip distance of the assumed cutoff locking coefficient $\phi_{c}$ (Fig. 2c), fault coseismic slip behavior is largely affected by the choice of $h^{*}$. In the initial setup, we use a uniform $d_{c}=99.9 \mathrm{~mm}$ on the fault and find no earthquakes would appear in the central and southern segments. This is because the resulting $W / h^{*}$ is too small to generate earthquakes in the central Cascadia. In the following, we reduce $d_{c}$ to $33.3 \mathrm{~mm}$ in the central and southern segments (between $-700 \mathrm{~km}$ and $50 \mathrm{~km}$ ) and $d_{c}$ remains $99.9 \mathrm{~mm}$ in the northern segment ( 50 to $400 \mathrm{~km}$ ). 

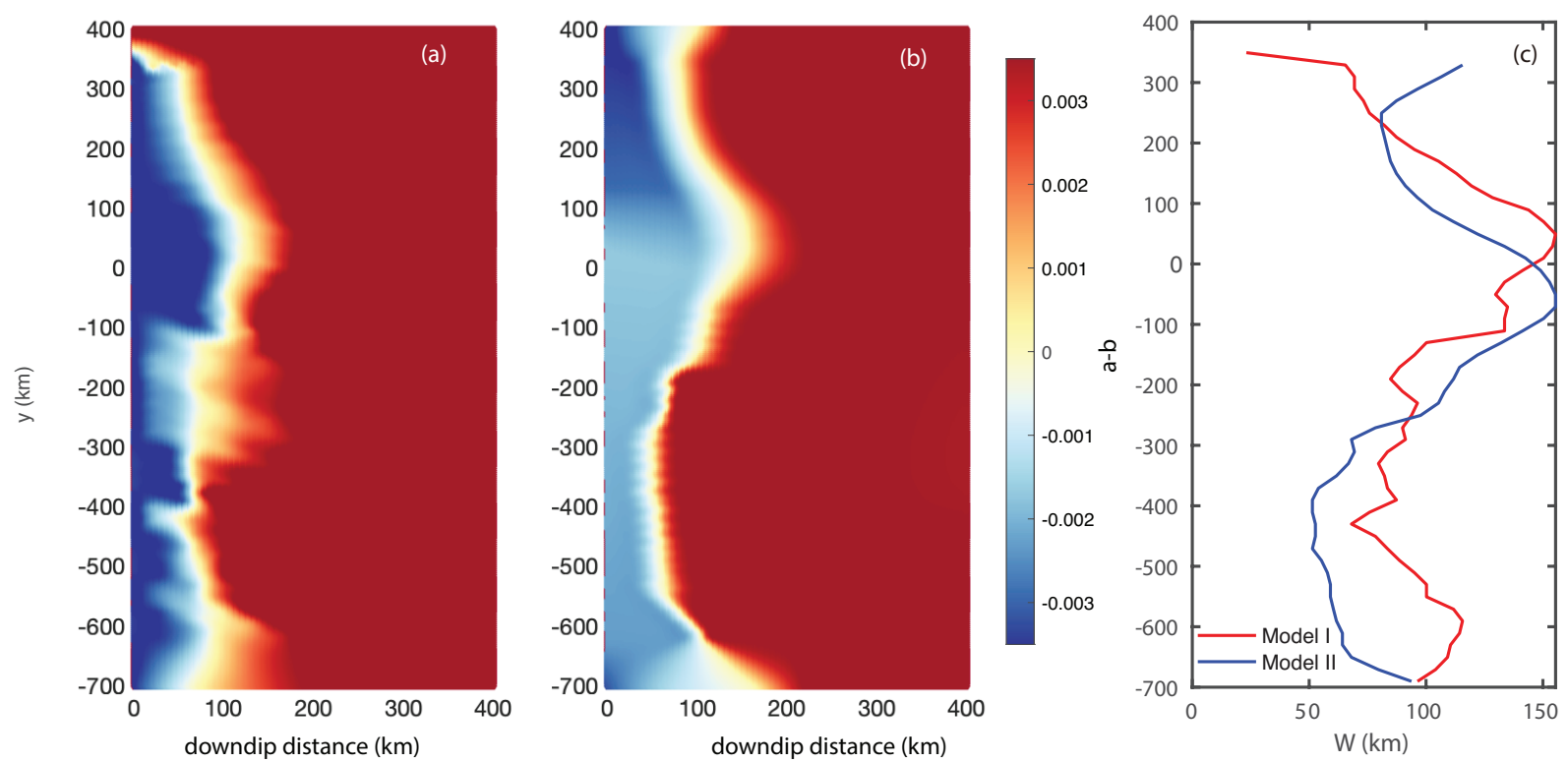

Figure 2: Maps showing non-dimensional frictional parameter $a-b$ of (a) Model I (Schmazle et al., 2014) Parameter $a-b$ linearly increases from -0.0035 to 0 from trench to downdip limit of seismogenic zone. (b) Model II (Burgette et al., 2009). Parameter $a-b$ linearly increases from -0.0035 to 0 as $\phi$ decreasing from 1 to 0.5 . Trench is not firmly locked in Burgette model. (3) Downdip distance of velocity-weakening portion in model I (red) and Model II (blue).

The revised model results in a heterogeneous $W / h^{*}$, specifically larger $W / h^{*}$ in the central and southern segments, which lead to margin-wide coseismic ruptures. We also test $d_{c}=49.9 \mathrm{~mm}$ in the central and southern segments while keeping other parameters constant. Table S1 lists the $d_{c}$ values used in three different tests for Model I.

For Model II, we use a slightly different setup for $d_{c}$. $d_{c}=33.3 \mathrm{~mm}$ is used between $-700 \mathrm{~km}$ and $200 \mathrm{~km}$ as the firmly locking segment is further northwards. $d_{c}=99.9 \mathrm{~mm}$ is used for northern Cascadia (-180 to $400 \mathrm{~km})$.

Effective normal stress $\bar{\sigma}$ The effective normal stress $\bar{\sigma}$ is set to be $5 \mathrm{MPa}$ at the trench, linearly increases to $50 \mathrm{MPa}$ at $2.7 \mathrm{~km}$ (vertical depth) and then kept at $50 \mathrm{MPa}$ further downdip. For simplicity, we also assume such downdip distribution of $\bar{\sigma}$ is uniform along the strike direction, although spatial heterogeneities are likely more realistic due to influence from the overlying geologic terranes [17, 36].

\section{Results}

In this section, we introduce the cumulative slip and slip rate history for a total of 1600-year simulation period in Model I and Model II. Here, coseismic slip is defined when the fault maximum slip rate exceeds a cutoff slip rate (i.e. $V_{s r} \geq 1 \mathrm{~mm} / \mathrm{s}$ ). We will then select modeled whole-margin earthquake ruptures to show the coseismic slip distribution on the fault and the resulting subsidence at the coastal sites for comparison with the historical observations in Wang et al.[11]. 
Model I Fig. 3 shows the cumulative slip history at downdip distance $20 \mathrm{~km}$. In the entire 1600 year simulation period, six margin-wide earthquakes appear with similar rupture lengths. The maximum along-strike rupture length is up to $1000 \mathrm{~km}$. The average recurrence interval of these quasi-periodic earthquakes is about $\sim 250-300$ years (Fig. $3 \mathrm{~b}$ ).

The maximum coseismic slip reaches up to $25 \mathrm{~m}$ due to the largest seismogenic zone width in the northern segment $([-180 \mathrm{~km}, 400 \mathrm{~km}])$. Relatively smaller coseismic slip, up to $15 \mathrm{~m}$, appears in the central segment $([-400 \mathrm{~km},-180 \mathrm{~km}])$ due narrower seismogenic zone width. The narrow $W$ is to some degree compensated by the choice of $d_{c}$ one third of that in the northern segment. Using the same large $d_{c}$ would effectively stop rupture from propagating through the central segment (Fig. S10).

We calculated the total coseismic slip (accumulated over the time period when $V_{\max }>V_{s r}$ ) and moment magnitude for each of the modeled megathrust events. The seismic moment is obtained using:

$$
M_{0}=\Sigma_{i} \mu \delta_{i} A_{i}
$$

where $\mu$ is assumed shear modulus of $30 \mathrm{GPa}, \delta_{i}$ and $A_{i}$ are total slip and area of an individual element $i$. The coseismic slip distribution of EQ4 (Fig. 3) of Mw8.9 is shown in Fig. 5a. Coseismic slip of 10-12 m extends $\sim 900 \mathrm{~km}$ along the trench, and propagates to an average downdip distance of $\sim 100 \mathrm{~km}$, which is in general consistent with the downdip distribution of the friction parameter $a-b$ (Fig. 2a) as inferred from the geodetic locking coefficient. We further show the cumulative slip of an Mw9.0 and Mw9.1 event in Fig. S6a and Fig. S7a, respectively. The estimated magnitudes of the six earthquakes shown in Fig. 5b are in the range of Mw8.9-9.1. Earthquake source statistics, including occurrence times, magnitudes, and along-strike rupture lengths, of each individual event is listed in Table S2.

To further test the influence of along-strike heterogeneous $d_{c}$, we set $d_{c}=49.9 \mathrm{~mm}$ in the central and southern segments. As in Fig. S3, the slightly higher $d_{c}$ (hence smaller $W / h^{*}$ ) leads to shorter rupture segments instead of margin-wide events. A margin-wide rupture occasionally appear and repeats at about $650 \mathrm{yr}$ (Fig. S3, Table S3), which is twice of the average recurrence time for the model with $d_{c}=33.3 \mathrm{~mm}$. Segmented, smaller ruptures appear every $150-400 \mathrm{yr}$ (Fig. S3). The magnitudes and times of each rupture are listed in Table S3.

Model II Fig ta shows that more complex earthquake sequences appear in Model II, which indexes $a-b$ to the Burgette2009 locking model. The maximum slip is up $18 \mathrm{~m}, 6 \mathrm{~m}$ and 12 $\mathrm{m}$ in the northern, central, and the southern segment, respectively (Fig. 4a). Model II has a maximum fault locking between $47^{\circ} \mathrm{N}$ and $50^{\circ} \mathrm{N}$ (Fig. 1 $1 \mathrm{~b}$ ); thus, the coseismic rupture extends further northwards than that in Model I. On the contrary, the locked fault is shallower and results in narrower seismogenic zone in the central segment (Fig.2c). Thus there are fewer margin-wide ruptures in Model II, although the same $d_{c}=33.3 \mathrm{~mm}$ is used between $50 \mathrm{~km}$ and $-700 \mathrm{~km}$ (Fig. A) a. More segmented ruptures emerge between -600 and $-100 \mathrm{~km}$.

Several coseismic segments are separated by less than one day in the simulation, and thus are merged in the total coseismic slip and moment magnitude calculation. Fig. S8 shows the coseismic slip distribution of a possible margin-wide earthquake of Mw9.0 at year 649 in Model II. Due to the multi-hour time separation and sluggish nature of the quasi-dynamic approach, we caution that in reality this may correspond to two closely linked but separate ruptures along the subduction margin.

We show two additional tests of Model II to demonstrate the sensitivity of earthquake sequence on different choices of the cutoff locking coefficient $\phi_{c}$. Fig. S1 and S2 represent earthquake sequences using $\phi_{c}=0.4$ and 0.5 , respectively. The higher $\phi_{c}$ used, the narrower downdip distance 

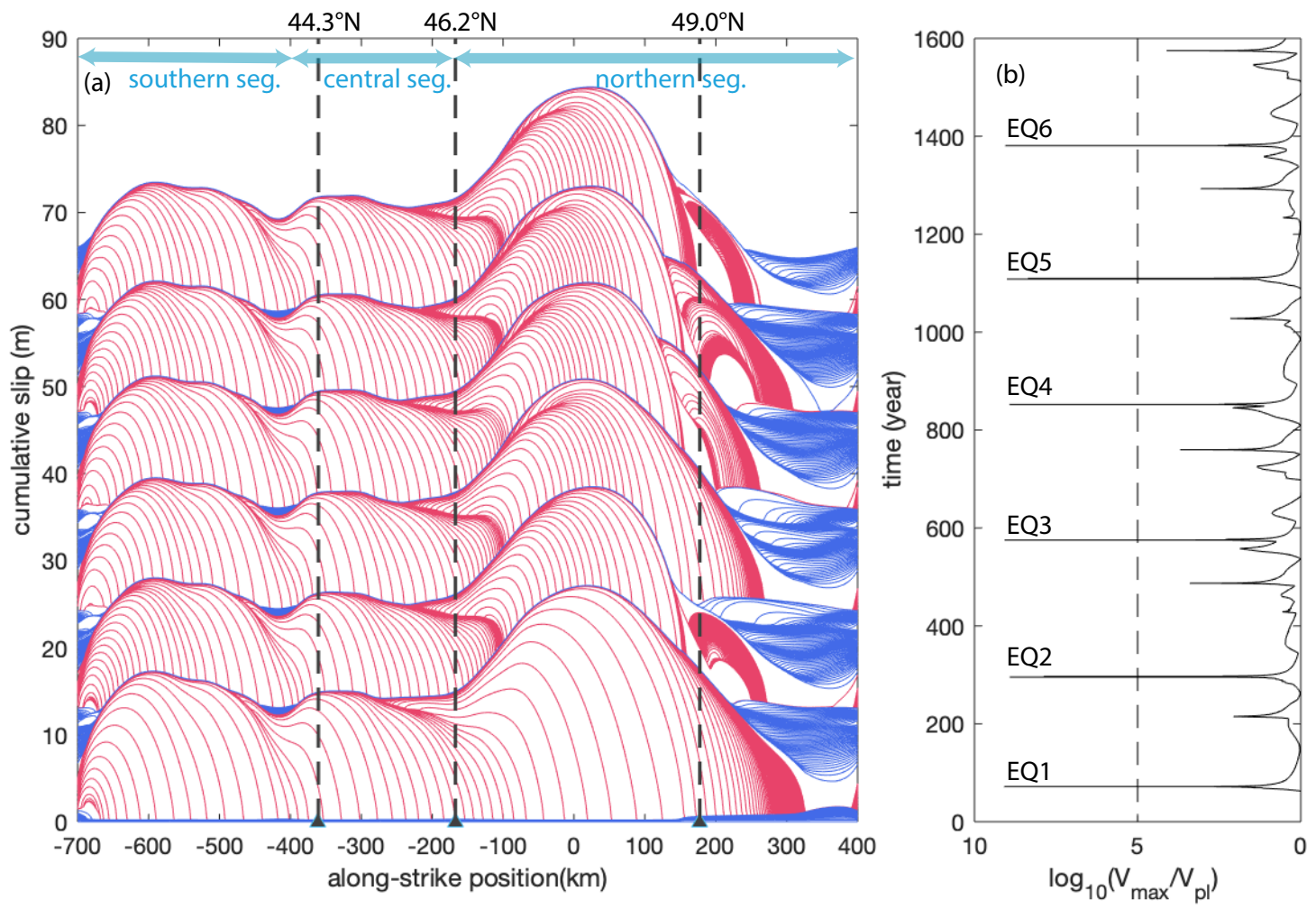

Figure 3: (a) Coseismic slip (red lines) of every $30 \mathrm{sec}$ for 6 earthquakes in a 1600-year simulation history of Model I. Interseismic slip (blue lines) of every 2 year is shown. Seven coseismic rupture segments are identified with text labels EQ1 to EQ6. The northern, central and southern segments are denoted at the top, respectively. The segmentation is based on Schmalzle el at.[2014][5]. (b) Maximum slip rate $\log _{10}\left(V_{\max } / V_{p l}\right)$ of 6 earthquakes. Smaller peaks represent possible aseismic slip appearing along the fault (dashed line).

of velocity weakening portion. Only the northern part of the fault could simultaneously generate coseismic rupture as the central and southern parts have limited seismogenic zone downdip widths (Fig. 2c).

Synthetic subsidence data We use the coseismic slip distribution on the subduction fault to calculate the synthetic surface subsidence using Okada's dislocation method with the assumption of a half-space homogeneous Earth [48]. A uniform Poisson's ratio of 0.25 and shear modulus 30 GPa are used.

In Fig. $5 \mathrm{~b}$ (Model I), synthetic subsidence compares well with the observation data points within their uncertainty ranges. The agreement is in particular good in the range between -300 $\mathrm{km}$ and $200 \mathrm{~km}$. On the sites between -700 and $-300 \mathrm{~km}$, synthetic subsidence calculations are generally larger than the field measurements, although there are also relatively large uncertainties at the two southernmost sites, Sixes River and California Humboldt Bay, as no transfer functions correction is applicable due to insufficient data coverage [11].

Additional synthetic subsidence calculations from modeled earthquakes of Mw9.0 to Mw9.1 are shown in Fig. S6b and Fig. S7b, respectively. Compared with Fig.5b, increasing moment 

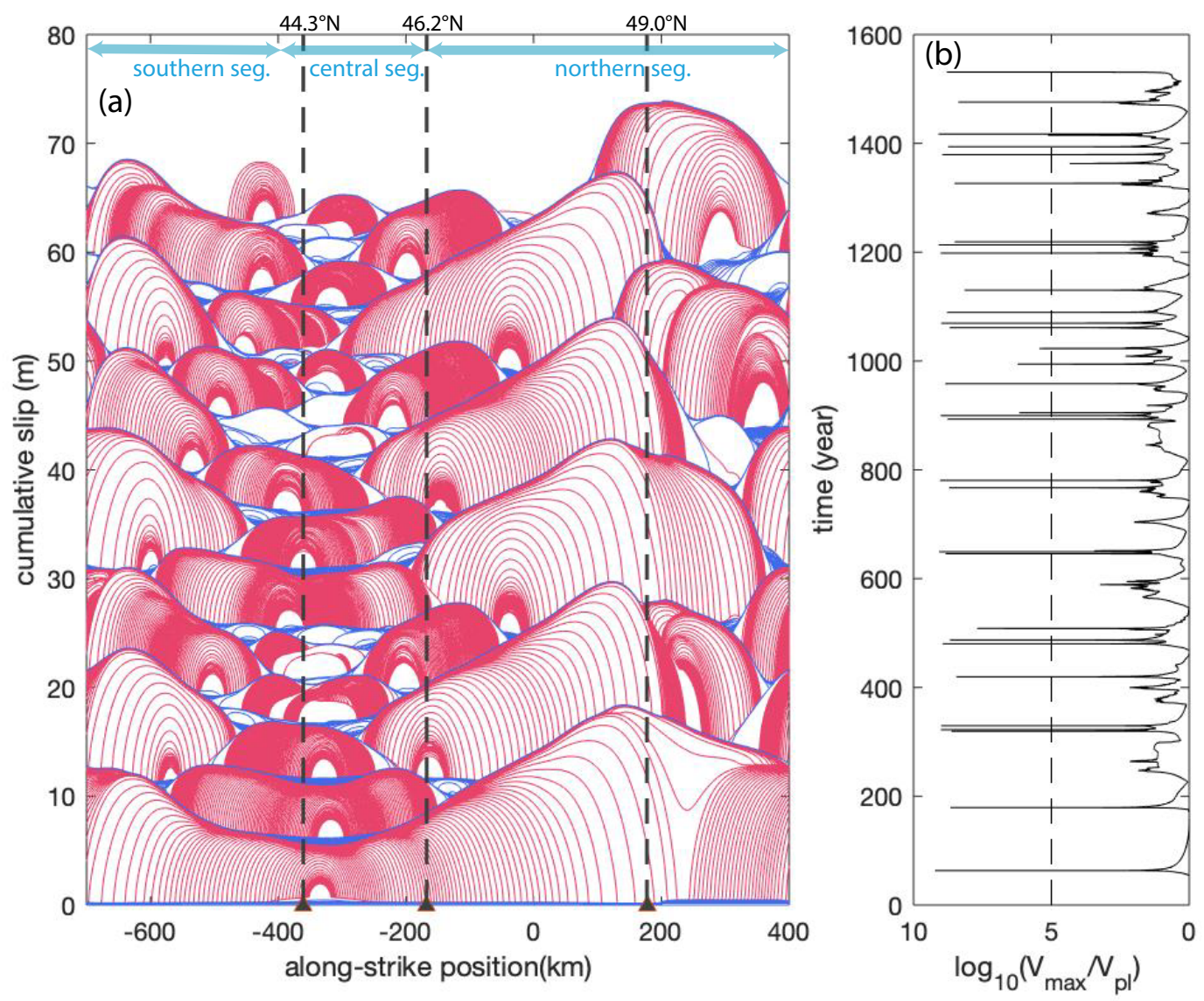

Figure 4: (a) Coseismic slip (red lines) of every $30 \mathrm{sec}$ for coseismic slip in Model II. Interseismic slip (blue lines) of every 2 year is shown. (b) Maximum slip rate $\log _{10}\left(V_{\max } / V_{p l}\right)$ during 1600 year.

magnitudes result in larger subsidence at all stations and less comparable with the observations.

Fig. S8 shows the synthetic subsidence calculated from the coseismic slip slip of a possible margin-wide earthquake of Mw9.0 for Model II. The subsidence between $-400 \mathrm{~km}$ and $-100 \mathrm{~km}$ is too small, even consider the uncertainty range. Thus we consider that the coseismic slip of Model II cannot reproduce the observational subsidence.

Synthetic interseismic fault locking We also calculate the fault locking coefficient using a 100-year interseismic slip history in each model. The 100-year window is chosen to be sufficiently distanced from any earthquake-related slip (e.g., nucleation, post-seismici slip) on the entire fault. First, we sum up the modeled slip on the fault over 100 years $\delta_{100}$. Then we calculate the fault locking coefficient using: $\phi_{m o d}=\frac{V_{p l} T-\delta_{100}}{V_{p l} T}$ where $T=100$ year. The fault locking results of Model I and Model II are shown in Fig. S9. Both patterns are in general the same as the input frictional instability parameter $a-b$ shown in Fig. 2, confirming its control on the overall earthquake rupture pattern and importance of incorporating geodetic locking model in earthquake sequence simulations. 


\section{Discussions}

Along-strike variation in characteristic nucleation size $h^{*}$ The ratio between seismogenic zone and earthquake nucleation size $W / h^{*}$ mostly affects the partition between aseismic and coseismic slip modes, as shown by previous simulations for earthquake sequences [40] and transient slow slip events modeling [38, 39, 51]. Source characteristics including recurrence interval, cumulative slip, and magnitude scale roughly with $W / h^{*}[34,39]$. In our model, the downdip width of the seismogenic (velocity-weakening) zone $(W)$, is constrained using geodetically determined fault locking coefficient $\phi$ by assuming friction instability transition takes place at different thresholds $\phi_{c}$, which is kept constant with time. Thus, the along-strike heterogeneity of $h^{*}\left(\right.$ or $\left.d_{c}\right)$ affects the modeled earthquake nucleation process.

In our model, the narrowing $W$ in the central and southern segments requires a reduced nucleation zone size $h^{*}$ (or $d_{c}$ ) compared to that of the northern segment in order to achieve a continuous margin-wide rupture. Specifically, we find that $h^{*}$ reduced by a factor of 3 in central Cascadia could result in a continuous coseismic rupture in Model I (Fig. 3). The model using reduced $d_{c}$ by a factor of 2 leads to smaller earthquake segments instead of frequent margin-wide events (Fig. S3). Cascadia rupture calculated from paleoseismic evidence might indicate a combination of the two scenarios [2]. In this case, margin-wide rupture and segmented rupture might both appear. In addition, the reduced $d_{c}$ is assumed to be uniform between $-700 \mathrm{~km}$ and $50 \mathrm{~km}$. Additional, smaller wave-length heterogeneities in the central and southern Cascadia on the top of the oceanic slab may further complicate and influence the choice of $d_{c}$ that determines whether rupture can propagate through or be arrested.

Although the physics of $d_{c}$ on natural faults is not clear, the along-strike variation of $d_{c}$ may reflect the heterogeneous characteristics of different geological terranes, the Wrangellia, Siletzia, and Klamath terranes from north to south along the Cascadia margin. The Siletzia terrane (between $46^{\circ} \mathrm{N}$ and $43^{\circ} \mathrm{N}$ ) is an accretion of Eocene age basalt with less permeability, which may increase pore fluid pressure and promote partial creeping on the megathrust fault [5, and therein referred]. In this conceptual model, the less porous overlying plate may lead to smaller slip during both earthquakes and slow slip events than elsewhere along the margin. The hypothesis of along-strike variable permeability can explain the inferred wider transition zone between the fully locked and continuous creeping offshore Oregon. It also reconciles with the observed gravity anomalies that correlate with slow slip segmentation along the strike [17, 41]. Brudzinski and Allen [17] proposed that the gravity anomalies reflect the density and porosity of the overlying plate, which may affect the fault hydrous condition through permeability. The coastal observed uplift rates require nonzero shear stress loading at the base of the locked zone [10]. More recently, Bodmer et al. [16] related the geodetic locking variation in the three Cascadia terranes to the asthenospheric buoyancy of subducting plate, which influences the overlying plate topographic development and along-strike variation of strain accumulation in earthquake cycles.

Except for megathrust earthquakes that have ruptured the entire Cascadia margin, partial ruptures appeared along various segments of the margin [2, 3]. For example, it is likely that several historical earthquakes only ruptured along the Oregon and northern California segments [3]. Why did those segmented earthquakes fail to rupture the entire fault? Is it possible that a whole-fault rupture could occasionally result from several smaller segmented ruptures via dynamic weakening on a subduction fault like Cascadia? The questions are difficult to answer without direct observations of fault mechanical properties or time-dependent rupture records. But several lines of evidence suggest that coseismic rupture may be driven by dynamic weakening within a creeping section on a fault, even though earthquakes cannot spontaneously nucleate there [47]. For example, the 1999 Mw7.6 Chi-Chi earthquake nucleated in the southern part of the Chelungpu fault, while rupture 
propagated mainly to the north reaching the maximum slip whereas borehole rock samples revealed velocity-strengthening behavior there (that is, a previously creeping section) [42]. The along-strike rupture pattern can be explained in a numerical model by introducing dynamic weakening due to efficient thermal pressurization in the northern segment [47]. Dynamic earthquake models that fully capture the coseismic stress transfer process in rupture propagation, with possibly enhanced weakening mechanisms such as thermal pressurization, are necessary to fully investigate the detailed megathrust earthquake rupture scenarios in Cascadia.

Fault locking models We showed that Model I with frictional stability parameter $a-b$ constrained by the fault locking model from the inversion of continuous GPS records (with vertical reference frame adjusted to nearby tidal gauge and leveling uplift rates) [5] can reproduce coseismic ruptures across the entire margin and generate surface displacements that agree reasonably with the coastal subsidence data (Figs. 5). On the contrary, Model II, in which fault locking pattern informed from tidal gauge and leveling data, generate more segmented earthquakes and show less frequent appearances of margin-wide rupture (Fig. 4 and S1). We thus propose that the utilization of various types of surface displacement data as in Model I may provide more realistic constraints to the downdip limits of the locking zone that are critical for earthquake sequence models.

However, fault locking models are usually less accurate for the shallow near-trench depths [12]. The lack of near-trench geodetic observation leaves the shallow fault locking status poorly constrained. For example, offshore Tohoku of the northeast Japan trench, the fault locking inversions with land-based GPS stations showed no strong coupling within $100 \mathrm{~km}$ landward from the trench [21]. However, the $2011 \mathrm{M} 9.1$ Tohoku-Oki earthquake rupture started at $40 \mathrm{~km}$ landward from the trench where the fault was estimated to have low coupling coefficients [21, 54]. Additionally, Wallace et al. [56] found several shallow slow slip events (within $7 \mathrm{~km}$ beneath seafloor) in the Hikurangi subduction zone using absolute pressure gauge (APGs) networks. The detection of shallow SSEs suggests that the shallow part of a megathrust fault might also undergo conditionally stable slip if the rock frictional properties transition from velocity-weakening to velocity-strengthening, in a similar manner to its downdip counterpart. In that case, the conditionally-stable shallower portion can still host large coseismic slip, as evidenced by the 2011 Tohoku-Oki M9.1, when the downdip rupture propagates into the low-confining pressure and low-strength part of the fault near the trench [24].

Most current geodetic models for subduction zones need to assume that the megathrust fault is firmly locked (about 100\%) at the trench and decreases with landward distance [e.g. 5]. The fault locking models will be different when using different mathematical formations with depth (e.g. Gaussian or Gamma distribution) to constrain the downdip variation [5]. The estimation of fault locking patterns can affect potential earthquake and tsunami hazard assessment for subduction zones. Until we have sufficient seafloor geodetic observation, the updip limit and hence the entire width of the seismogenic zone is not well constrained. In addition, taking viscoelastic stress relaxation into consideration also results in a significant difference from the elastic dislocation model commonly used in geodetic inversion studies [12].

\section{Conclusions}

Due to the lack of modern seismological records, the downdip extent of the seismogenic zone in Cascadia is still obscure. To understand the historical seismic records and their implications for potential future ruptures, we model Cascadia megathrust earthquake cycles in the laboratoryderived rate-and-state friction framework. The seismogenic zone is constrained by two types of fault 
locking models, represented by the coupling coefficient $\phi$, obtained from geodetic inversion studies. Specifically, we use the fault locking model derived from continuous Plate Boundary Observatory GPS measurement (with vertical reference frame adjusted to nearby tidal gauge and leveling uplift

rates) [5] and tidal gauge and leveling records along the Cascadia margin [18]. The two locking models show considerable differences in the amplitude and along-strike distribution. Our main conclusions based on the model results and comparison to coastal subsidence data are:

1) The extent of coseismic rupture is mainly controlled by the downdip width $W$ of the velocityweakening $(a-b<0)$ zone, which is constrained by the fault locking coefficient $\phi$. The northern segment with the widest seismogenic zone, due to its shallower dipping angle, generates the largest coseismic slip. The coseismic slip is relatively smaller in the central and southern segments where $W$ is narrower.

2) With the above locking coefficient constrained $a-b$ distribution, an along-strike uniform nucleation zone size $h^{*}$ cannot generate margin-wide ruptures that are necessary to reproduce the coastal subsidence observations from the A.D. 1700 Cascadia earthquake. Rather, rate-state characteristic slip distance $d_{c}$, proportional to $h^{*}$, in the central and southern segments needs to be set at least one third of that in the northern segment, for a rupture to propagate through the entire margin in Model I. The same reduction in $d_{c}$ in Model II would still result in segmented ruptures. Heterogeneous distribution of $d_{c}$ and/or effective normal stress $\left(h^{*} \propto d_{c} / \bar{\sigma}\right)$ could be related to along-strike variation of the geological terranes of the overlying plate.

3) Coseismic slip from the margin-wide earthquake rupture in Model I leads to synthetic surface displacements in reasonable agreement with the coastal subsidence observation of the A.D. 1700 earthquake, although our simplified elastic half-space model with spatially uniform elastic moduli may contribute to some of the discrepancies between the modeled and observed subsidence.

Due to the lack of near-trench geodetic observation, our model only focuses on the downdip extent of Cascadia megathrust rupture. Future seafloor displacement monitoring of the offshore Cascadia is critical for a more realistic and comprehensive assessment of the Cascadia megathrust earthquak and tsunami harzrads.

Data Access Data products can be accessed on Open Science Framework at https://osf.io/b2qcx

Competing The authors declare that they have no competing interests.

Funding D. Li is financially supported by the European Research Council (ERC) under the European Union's Horizon 2020 research and innovation programme (ERC Starting Grant TEAR agreement No. 852992) and the German Research Foundation (DFG project grants no. GA 2465/21, GA 2465/3-1)). Y. Liu is supported by the Natural Sciences and Engineering Research Council of Canada Discovery Grant RGPIN-2018-05389 at McGill University. Computing resources were provided by the Institute of Geophysics of LMU Munich [58] and the Leibniz Supercomputing Centre (LRZ, projects no. pr63qo and pr45fi on SuperMUC).

Acknowledgements We thank two anonymous reviewers and Editor K. Uenishi for their constructive suggestions and comments.

\section{References}

[1] Scholz H. Earthquakes and friction laws. Nature, 391, 1998.

[2] Goldfinger C, Grijalva K, Bürgmann R, Morey AH, Johnson J, Nelson CH, Gutiérrez-Pastor J, Ericsson A, Karabanov E, Chaytor JD, et al. Late holocene rupture of the northern san andreas fault and possible stress linkage to the cascadia subduction zone. Bulletin of the Seismological Society of America, 98(2):861-889, 2008. 
[3] Leonard LJ, Currie CA, Mazzotti S, and Hyndman RD. Rupture area and displacement of past cascadia great earthquakes from coastal coseismic subsidence. Geological Society of America Bulletin, 122(11-12):2079-2096, 2010.

[4] Satake K. Depth distribution of coseismic slip along the Nankai Trough, Japan, from joint inversion of geodetic and tsunami data. J. Geophys. Res., 98(B3):4553-4565, 1993.

[5] Schmalzle GM, McCaffrey R, and Creager KC. Central cascadia subduction zone creep. Geochemistry, Geophysics, Geosystems, 15(4):1515-1532, 2014.

[6] Atwater BF, Nelson AR, Clague JJ, Carver GA, Yamaguchi DK, Bobrowsky PT, Bourgeois J, Darienzo MK, Grant WC, and Hemphill-Haley E. Summary of coastal geologic evidence for past great earthquakes at the cascadia subduction zone. Earthquake spectra, 11(1):1-18, 1995.

[7] Ludwin, Ruth S.,Dennis, Robert,Carver, Deborah,McMillan, Alan D. , Losey, Robert ,Clague, John ,Jonientz-Trisler, Chris,Bowechop, Janine , Wray, Jacilee and James, Karen, Dating the 1700 Cascadia Earthquake: Great Coastal Earthquakes in Native Stories. Seismological Research Letters, 2005.

[8] Hyndman RD and Wang K. The rupture zone of cascadia great earthquakes from current deformation and the thermal regime. J. Geophys. Res., 100(B11):22133-22154, Nov 1995.

[9] Hyndman RD, McCrory PA, Wech A, Kao H, and Ague J. Cascadia subducting plate fluids channelled to fore-arc mantle corner: Ets and silica deposition. Journal of Geophysical Research: Solid Earth, 120(6):4344-4358, 2015.

[10] Bruhat L, Segall P. Coupling on the northern Cascadia subduction zone from geodetic measurements and physics-based models. Journal of Geophysical Research: Solid Earth, 2016, 121(11): 8297-8314.

[11] Wang PL, Engelhart SE, Wang K, Hawkes AD, Benjamin P. Horton, Alan R. Nelson, and Robert C. Witter. Heterogeneous rupture in the great cascadia earthquake of 1700 inferred from coastal subsidence estimates. Journal of Geophysical Research: Solid Earth, 118(5):24602473, 2013.

[12] Wang K and Tréhu AM. Invited review paper: Some outstanding issues in the study of great megathrust earthquakes-The cascadia example. Journal of Geodynamics, 98:1 - 18, 2016.

[13] Ampuero J.-P. and Rubin A. M.. Earthquake nucleation on rate and state faults: Aging and slip laws. J. Geophys. Res., 113(B01302), 2008.

[14] Beeler NM , Tullisv TE, Blanpied ML , and Weeks JD. Frictional behavior of large displacement experimental faults. J. Geophys. Res., 101(B4):8697-8715, 1996.

[15] Blanpied ML, Tullis TE, and Weeks JD. Frictional behavior of granite at low and high sliding velocities. Geophysical Research Letters, 14(5):554-557, 1987.

[16] Bodmer M, Toomey DR, Roering JJ, and Karlstrom L. Asthenospheric buoyancy and the origin of high-relief topography along the Cascadia forearc. Earth and Planetary Science Letters, 531(115965):1-10, 2020.

[17] Brudzinski MR and Allen RM. Segmentation in episodic tremor and slip all along cascadia. Geology, 35(10):907-910, 2007. 
[18] Burgette RJ, Weldon RJ, and Schmidt DA. Interseismic uplift rates for western oregon and along-strike variation in locking on the cascadia subduction zone. Journal of Geophysical Research: Solid Earth, 114(B1), 2009.

[19] Chen X. and McGuire JJ, Measuring earthquake source parameters in the mendocino triple junction region using a dense obs array: Implications for fault strength variations. Earth Planet. Sci. Lett., 453:276-287, 2016.

[20] Dieterich J. H.. Modeling of rock friction 1. Experimental results and constitutive equations. J. Geophys. Res, 84(B5):2161-2168, 1979.

[21] Hashimoto C, Noda A, Sagiya T, and Matsu/'ura M. Interplate seismogenic zones along the kuril-japan trench inferred from gps data inversion. Nature Geosci, 2(2):141-144, 2009.

[22] Blanpied M. L., Marone C. J., Lockner D. A. , Byerlee J. D. and King D. P. , Quantitative measure of the variation in fault rheology due to fluid-rock interactions. Journal of Geophysical Research, 103(B5),1998.

[23] He C., Wang Z., and Yao W., Frictional sliding of gabbro gouge under hydrothermal conditions. Tectonophys., 445:353-362, 2007.

[24] Ide A, Baltay A, and Beroza GC. Shallow dynamic overshoot and energetic deep rupture in the $2011 \mathrm{mw} 9.0$ tohoku-oki earthquake. Science, 332(6036):1426-1429, 2011.

[25] Shibazaki, B., Obara, K., Matsuzawa, T., and Hirose, H., Modeling of slow slip events along the deep subduction zone in the Kii Peninsula and Tokai regions, southwest Japan: Journal of Geophysical Research,117.B6. 2012.

[26] Shibazaki B, Wallace L M, Kaneko Y, et al. Three-dimensional modeling of spontaneous and triggered slow-slip events at the Hikurangi subduction zone, New Zealand. Journal of Geophysical Research: Solid Earth, 124(12): 13250-13268. 2019.

[27] Matsuzawa, T., Shibazaki, B., Obara, K., and Hirose, H., Comprehensive model of shortand long-term slow slip events in the Shikoku region of Japan, incorporating a realistic plate configuration: Geophysical Research Letters, v. 40, no. 19, p. 5125-5130.2013.

[28] Wei, M., Kaneko, Y., Liu, Y., and McGuire, J. J., Episodic fault creep events in California controlled by shallow frictional heterogeneity: Nature Geoscience, v. 6, no. 7, p. 566-570. 2013.

[29] Wei M, Kaneko Y, Shi P, et al. Numerical modeling of dynamically triggered shallow slow slip events in New Zealand by the $2016 \mathrm{Mw} 7.8$ Kaikoura earthquake. Geophysical Research Letters, 45(10): 4764-4772,2018.

[30] Kaneko Y, Avouac J.P. , and Lapusta N. Towards inferring earthquake patterns from geodetic observations of interseismic coupling. Nature Geoscience, 3, 2010.

[31] Lapusta, N., Rice, J. R., Ben-Zion, Y., and Zheng, G., Elastodynamic analysis for slow tectonic loading with spontaneous rupture episodes on faults with rate-and state-dependent friction. Journal of Geophysical Research: Solid Earth (1978-2012), v. 105, no. B10, p. 23765-23789. 2000 .

[32] Lapusta N and Liu Y. Three-dimensional boundary integral modeling of spontaneous earthquake sequences and aseismic slip. J. Geophys. Res., 114(B09303), 2009. 
[33] Lapusta N and Rice JR. Nucleation and early seismic propagation of small and large events in a crustal earthquake model. J. Geophys. Res., 108(B4), 2003.

[34] Li D and Liu Y. Spatiotemporal evolution of slow slip events in a non-planar fault model for northern cascadia subduction zone. Journal of Geophysical Research: Solid Earth, 63(3):959$968,2016$.

[35] Okada Y. "Internal deformation due to shear and tensile faults in a half-space." Bulletin of the seismological society of America 82.2. 1018-1040. 1992.

[36] Li, D., and Liu, Y., Modeling slow-slip segmentation in Cascadia subduction zone constrained by tremor locations and gravity anomalies: Journal of Geophysical Research: Solid Earth, v. 122, p. $3138-3157.2017$.

[37] Liu Y and Rice JR. Aseismic slip transients emerge spontaneously in three-dimensional rate and state modeling of subduction earthquake sequences. J. Geophys. Res., 110(B08307), 2005.

[38] Liu Y. and Rice J.R., Spontaneous and triggered aseismic deformation transients in a subduction fault model. J. Geophys. Res., 112(B09404), 2007.

[39] Liu Y. and Rice J. R Slow slip predictions based on granite and gabbro friction data compared to GPS measurements in northern Cascadia. J. Geophys. Res., 114(B09407), 2009.

[40] Liu, Y., McGuire J. J. and Behn M. D. , Frictional behavior of oceanic transform faults and its influence on earthquake characteristics, Journal of Geophysical Research, 117(B4), 2012.

[41] Li, D., McGuire, J. J., Liu, Y., and Hardebeck, J. L., Stress rotation across the Cascadia megathrust requires a weak subduction plate boundary at seismogenic depths: Earth and Planetary Science Letters, v. 485, p. 55-64. 2018.

[42] Ma K-F, Brodsky E E, Mori J, Ji C, Song T, and Kanamori H. Evidence for fault lubrication during the 1999 chi-chi, taiwan, earthquake (mw7.6). Geophysical Research Letters, 30(5), 2003.

[43] Marone C, Laboratory-derived friction laws and their application to seismic faulting. Annual Review of Earth and Planetary Sciences, 26(1):643-696, 1998.

[44] McCaffrey, R., Time-dependent inversion of three-component continuous GPS for steady and transient sources in northern Cascadia: Geophysical Research Letters, v. 36, no. 7., 2009.

[45] McCrory PA, Blair JL, Waldhauser F, and Oppenheimer DH. Juan de Fuca slab geometry and its relation to Wadati-Benioff zone seismicity. J. Geophys. Res., 117(B09), 2012.

[46] McCrory, P. A., Hyndman, R. D., and Blair, J. L., Relationship between the Cascadia fore-arc mantle wedge, nonvolcanic tremor, and the downdip limit of seismogenic rupture: Geochemistry, Geophysics, Geosystems, v. 15, no. 4, p. 1071-1095. 2014.

[47] Noda H and Lapusta N. Stable creeping fault segments can become destructive as a result of dynamic weakening. Nature, 493(7433):518-521, 2013.

[48] Okada Y. Surface deformation due to shear and tensile faults in a half-space. Bulletin of the seismological society of America, 75(4):1135-1154, 1985. 
[49] Rice JR. Spatiotemporal complexity of slip on a fault. J. Geophys. Res., 98(B6):9885-9907, 1993.

[50] Rice JR and Ruina AL. Stability of steady frictional slipping. J. Appl. Mech., 50(2):343-349, 1983.

[51] Rubin AM. Episodic slow slip events and rate-and-state friction. J. Geophys. Res., 113(B11414), 2008.

[52] Rubin AM and Ampuero JP. Earthquake nucleation on (agine) rate and state faults. J. Geophys. Res., 110(B11312), 2005.

[53] Ruina AL. Slip instability and state variable friction laws. J. Geophys. Res., 88(B12):1035910370, 1983.

[54] Simons M, Minson SE, Sladen A, Ortega F, Jiang J, Owen SE, Meng L, Ampuero JP, Wei S, Chu R, Helmberger DV, Kanamori H, Hetland E, Moore AW, and Webb FH. The 2011 magnitude 9.0 tohoku-oki earthquake: Mosaicking the megathrust from seconds to centuries. Science, 332:1421-1425, 2011.

[55] Stuart W D, Hildenbrand T G, and Simpson R W . Stressing of the New Madrid Seismic Zone by a lower crust detachment fault. J. Geophys. Res., 102(B12), 1997.

[56] Wallace LM, Webb SC, Ito Y, Mochizuki K, Hino R, Henrys S, Schwartz SY, and Sheehan AF Slow slip near the trench at the hikurangi subduction zone, new zealand. Science, 352(6286):701-704, 2016.

[57] Yang H, Liu Y, and Lin J. Effects of subducted seamounts on megathrust earthquake nucleation and rupture propagation. Geophysical Research Letters, 39(24), 2012.

[58] Oeser, J. and Bunge, HP and Mohr, M., Cluster design in the Earth Sciences tethys. International conference on high performance computing and communications,pages:31-40, 2006. 

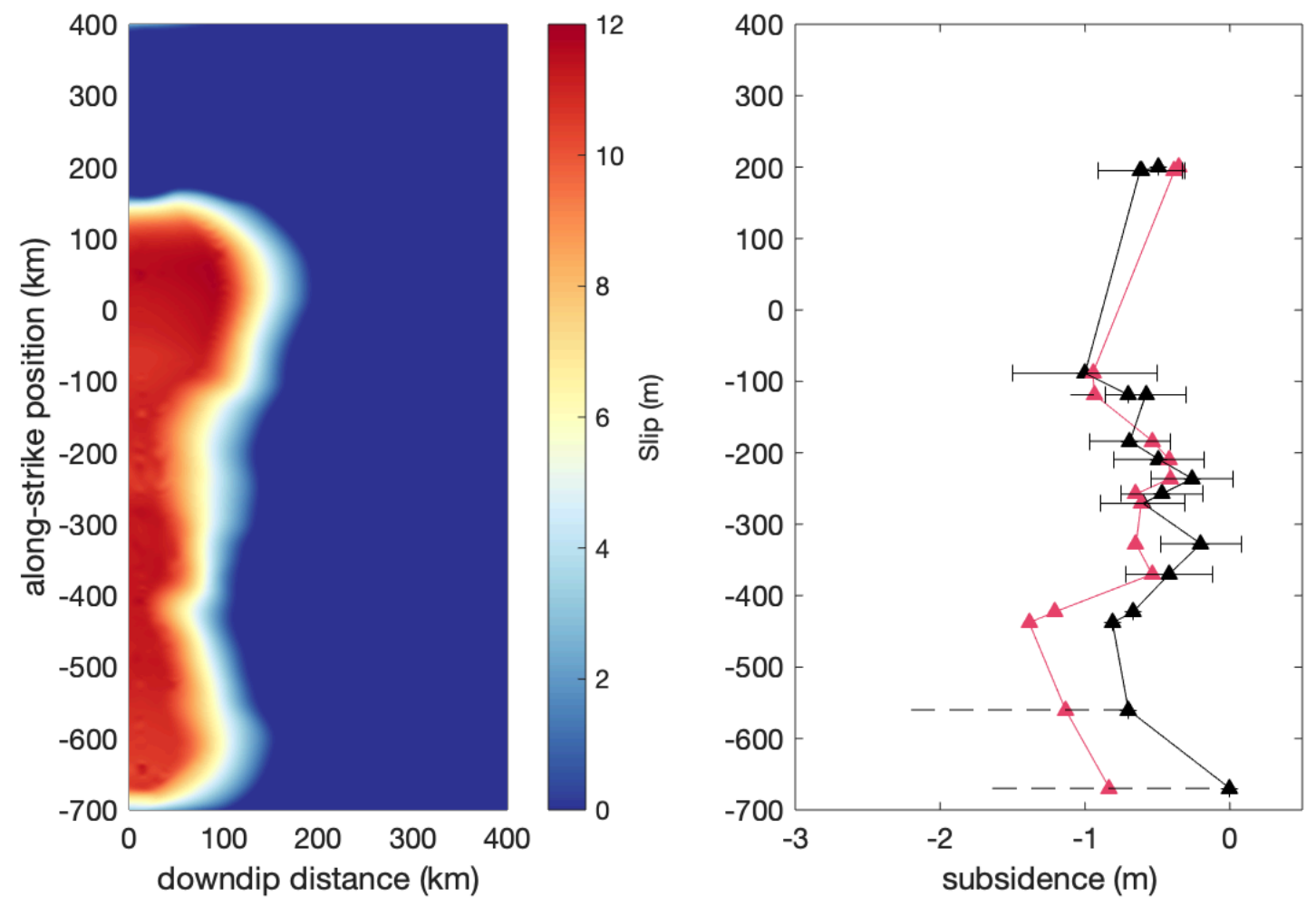

Figure 5: (a) Modeled coseismic rupture on the fault for EQ4 of Model I. The seismic moment magnitude is Mw8.9. (b) Red line: synthetic subsidences due to coseismic slip shown in (a). Black triangles with error bars: subsidence data from Wang et al. [2013] [11] with transfer function correction. Black triangles with dashed line: data range estimated without transfer function. 